\title{
Correlation of trace elements (serum zinc and copper) in type 2 diabetic patients with and without complications
}

\author{
Hiren Sanghani ${ }^{1}$, Vijaysinh Parmar ${ }^{2, *}$, Asha Khubchandani ${ }^{3}$ \\ ${ }^{1,2}$ Assistant Professor, ${ }^{3}$ Professor, Dept. of Biochemistry, ${ }^{1}$ GMERS Medical College, Gandhinagar, Gujarat, ${ }^{2}$ Smt. NHL \\ Municipal Medical College, Ahmedabad, Gujarat, ${ }^{3}$ B. J. Medical College, Ahmedabad, Gujarat, India
}

*Corresponding Author:

Email: drvijaysinhparmar@gmail.com

Received: $10^{\text {th }}$ October, 2017

Accepted: $13^{\text {th }}$ December, 2017

\begin{abstract}
Introduction: Type 2 diabetes mellitus (DM) is supposed to be associated with alteration in the serum levels of trace elements. Conversely, research also suggests that imbalances of specific elements associated with the complications of diabetes mellitus. Copper plays important role in oxidative stress and it's one of the important factor contributes to aetiology of DM. And zinc involved with synthesis \& secretion of insulin. So, we have choose copper and zinc to find association in diabetics patients.

Materials and Methods: In this cross sectional observational study total of one hundred and twenty (120) subjects were included and categorized into 3 groups. On the basis of screening, 80 patients were divided into two study groups: Group I (40 patients with micro- or macrovascular complications) and Group II (40 diabetic patients without complications). Group III include the 40 age and sex matched non-diabetic healthy control subjects selected for comparison. Serum zinc, copper concentration and $\mathrm{HbA1c} \%$ (glycated haemoglobin) were estimated in all three study groups.

Result: Serum copper concentration and $\mathrm{HbA1c} \%$ were significantly $(\mathrm{p}<0.05)$ higher in diabetic patients (with and without complication) compared to control group. And serum copper shows significant $(\mathrm{p}<0.01)$ positive correlation with $\mathrm{HbAlc} \%$ in both diabetic study groups. Serum zinc concentration was significantly $(\mathrm{p}<0.05)$ lower in diabetic patients (with and without complication) compared to healthy control group. And serum zinc shows significant $(\mathrm{p}<0.01)$ negative correlation with $\mathrm{HbA1c} \%$ in both diabetic groups.

Conclusion: Alteration in levels of trace elements (like, $\mathrm{Zn}$ and $\mathrm{Cu}$ ) are found to be important influencing factors for diabetic patients for developing complications. From the present study, it may be determined that altered levels of trace elements (like zinc and copper) may have contributory a role in the pathogenesis and progression of type $2 \mathrm{DM}$.
\end{abstract}

Keywords: Diabetes mellitus, Serum copper, Serum zinc, HbA1c\%.

\section{Introduction}

In 2000, India (31.7 million) topped the world with the highest number of people with diabetes mellitus followed by China (20.8 million) with the United States (17.7 million) in second and third place respectively. According to Wild et $\mathrm{al}^{1}$ the prevalence of diabetes mellitus is predicted to almost double globally from 171 million in 2000 to 366 million in 2030 with a maximum increase in India. It is projected that by 2030 diabetes mellitus burden may raised up to 79.4 million individuals in India, while China (42.3 million) and the United States (30.3 million) will also see significant increases in those affected by the disease. ${ }^{1}$

Diabetes mellitus is an endocrinological disorder characterized by hyperglycaemia and glycosuria due to either absolute or relative deficiency of insulin, which leads to metabolic derangement of carbohydrates, fats, proteins, water and electrolytes. ${ }^{2}$ Type 2 diabetes mellitus is mostly due to insulin resistance and/or insulin secretory defects, and accounts for almost $90 \%$ of all diabetic cases. ${ }^{3}$ The persistence hyperglycaemia in chronic diabetics and persistence of these metabolic derangements are associated with long term damage of different organs. Cumulative effect of these changes in turn lead to development of various complications. Due to hyperglycaemia gradual changes may develop over a period of time which may affect especially the heart, kidneys, eyes, blood vessels, skin and the nervous system. ${ }^{4}$ The persistence hyperglycaemia in chronic diabetics is associated with vascular (micro and macro) and nonvascular complications. The microvascular complications of DM include neuropathy, nephropathy and retinopathy; while macrovascular complications include coronary artery disease, cerebrovascular disease, peripheral arterial disease. ${ }^{2}$

Trace elements are essential substances for optimum human health, because of their diverse metabolic characteristics and functions. ${ }^{4}$ A relationship between DM and various trace elements (like copper, zinc, selenium and magnesium) is frequently reported in various studies. ${ }^{2-4}$ Trace elements participate in various metabolic processes and produce numerous reactive oxygen species (ROS), which contribute to oxidative stress. Oxidative stress is one of the etiological factor that is responsible for the pathogenesis of many non-communicable diseases including DM. ${ }^{5}$

Zinc $(\mathrm{Zn})$, an essential trace element, serves as a co-factor for hundreds of enzymes, those regulate the metabolism of carbohydrate, lipids and proteins ${ }^{6}$. Zinc is involved in the synthesis and storage, of insulin. Zinc also maintain the structural integrity of insulin. It has 
been found that zinc enhance the effectiveness of insulin in vitro. ${ }^{4}$ Zinc also plays important role in glucose metabolism. There is supporting evidence that zinc metabolism is altered in the course of diabetes mellitus and that altered zinc metabolism contributes to pathogenesis and progression of disease. ${ }^{3}$

Copper $(\mathrm{Cu})$, is the third most abundant essential trace element in the body. Copper is present in the body is important for the metalloenzymes such as ceruloplasmin and superoxide dismutase (SOD). These enzymes play major roles in oxidation-reduction reactions and in antioxidant defence mechanism. ${ }^{3}$ Copper acts as a pro oxidant and produces free radicals and reactive oxygen species which are likely to be associated with development of type 2 DM. ${ }^{5}$ It has been hypothesized that copper has insulin-like activity and promotes lipogenesis. Human studies demonstrate that diabetic patients may have abnormal levels of serum copper. $^{3}$

Historically, glycosylated haemoglobin (HbA1c\%) has been recommended only for the determination of glucose control among persons who are known diabetics. New clinical practice recommendations from the American Diabetes Association encourage the use of $\mathrm{HbA} 1 \mathrm{c} \%$ in the diagnosis of diabetes, largely on the basis of the established association between $\mathrm{HbA} 1 \mathrm{c} \%$ and microvascular disease. ${ }^{7}$

The present study was aimed to evaluate the serum zinc, copper and $\mathrm{HbA1c} \%$ levels in type 2 diabetes mellitus patients with and without complications. Also, it was intended to identify the correlation of these trace elements (serum zinc and copper) with $\mathrm{HbA1c} \%$ in diabetic patients.

\section{Materials and Methods}

A total of eighty (80) patients with confirmed type2 diabetes mellitus for the duration 10-15 years were enrolled for the cross sectional observational study conducted in Biochemistry Department, BJ Medical College and Civil Hospital, Ahmedabad from February
2013 to September 2013. The diagnosis of patients with type-2 diabetes mellitus was confirmed by biochemical investigations as per WHO criteria. Their detailed clinical history was taken and screened clinically for the presence of micro or macrovascular complications like, nephropathy, neuropathy, retinopathy, coronary artery disease and peripheral vascular disease. On the basis of screening, 80 patients were divided into two study groups: Group I (40 patients with micro- or macrovascular complications) and Group II (40 diabetic patients without complications). Group III include the 40 age and sex matched non-diabetic healthy subjects selected from the hospital staff and volunteer blood donors. Patients suffering from any acute infections, carcinoma, pregnant, lactating mothers, thyroid dysfunction and with history of chronic systemic disease were excluded from this study. After an overnight fast blood samples were collected from each individual for estimation of serum zinc, serum copper and $\mathrm{HbAlc} \%$ (glycated haemoglobin). Serum zinc \& serum copper level were estimated colorimetrically by using Di-Br-PAESA method in ERBA XL640 fully automated Biochemistry analyser. ${ }^{8,9} \mathrm{HbA} 1 \mathrm{c} \%$ estimation was done by ion exchange resin method. ${ }^{10}$

The SPSS 22.0 statistical package was used for data processing. Results obtained were summarized as mean ( \pm standard deviation). Differences between the groups were compared using Student t-test, and the level of significance was set at $\mathrm{p}<0.05$.

\section{Results and Observations}

A total of one hundred and twenty (120) subjects were included for the study. All subjects categorised in three groups as described in material and method. Table 1 shows demographic variables of all three groups. There was no significant $(\mathrm{p}>0.05)$ difference in age and BMI among all three groups. There was significant $(p<0.05)$ difference in duration of diabetes mellitus between group I and group II.

Table 1: Comparison of demographic variables among study groups

\begin{tabular}{|l|c|c|c|}
\hline & $\begin{array}{l}\text { Group I (Diabetics } \\
\text { with complication) }\end{array}$ & $\begin{array}{l}\text { Group II (Diabetics } \\
\text { without complication) }\end{array}$ & $\begin{array}{l}\text { Group III (Normal } \\
\text { Healthy Control) }\end{array}$ \\
\hline Number & 40 & 40 & 40 \\
\hline M/F & $20 / 20$ & $20 / 20$ & $20 / 20$ \\
\hline Age & $52.38 \pm 6.38^{*}$ & $50.45 \pm 5.16^{*}$ & $50.33 \pm 3.43^{*}$ \\
\hline BMI & $26.07 \pm 1.39^{*}$ & $25.71 \pm 1.52^{*}$ & $25.18 \pm 1.54^{*}$ \\
\hline Duration of DM & $12.95 \pm 1.45^{* *}$ & $11.13 \pm 1.20^{* *}$ & - \\
\hline
\end{tabular}

$* \mathrm{p}>0.05$ (Not significant), ${ }^{*} \mathrm{p}<0.05$ (Significant)

As presented in table 2 serum copper and $\mathrm{HbA1c} \%$ was significantly $(\mathrm{p}<0.05)$ higher in group I and II (respectively in diabetics with and without complication) compared to group III. And also, serum copper and $\mathrm{HbA} 1 \mathrm{c} \%$ was significantly $(\mathrm{p}<0.05)$ higher in diabetics with complication compared to without complication. Serum zinc was significantly $(\mathrm{P}<0.05)$ lower in group I and II (respectively in diabetics with and without complication) 
compared to group III. Also, serum zinc was significantly $(\mathrm{p}<0.05)$ lower in diabetic patients with complication compared to diabetics without complications.

Table 2: Comparison of biochemical parameters among study groups

\begin{tabular}{|l|c|c|c|}
\hline & $\begin{array}{l}\text { Group I (Diabetics } \\
\text { with complication) }\end{array}$ & $\begin{array}{l}\text { Group II (Diabetics } \\
\text { without complication) }\end{array}$ & $\begin{array}{l}\text { Group III (Normal } \\
\text { Healthy Control) }\end{array}$ \\
\hline Copper & $136.35 \pm 12.84^{*}$ & $125.18 \pm 10.31^{*}$ & $107.33 \pm 13.66^{*}$ \\
\hline Zinc & $83.18 \pm 7.95^{*}$ & $88.68 \pm 6.70^{*}$ & $101.93 \pm 10.67^{*}$ \\
\hline HbA1c\% & $9.83 \pm 1.45^{*}$ & $8.22 \pm 1.19^{*}$ & $5.09 \pm 0.52^{*}$ \\
\hline
\end{tabular}

$* \mathrm{p}<0.05$, Group I vs Group II, Group II vs Group III and Group I vs Group III

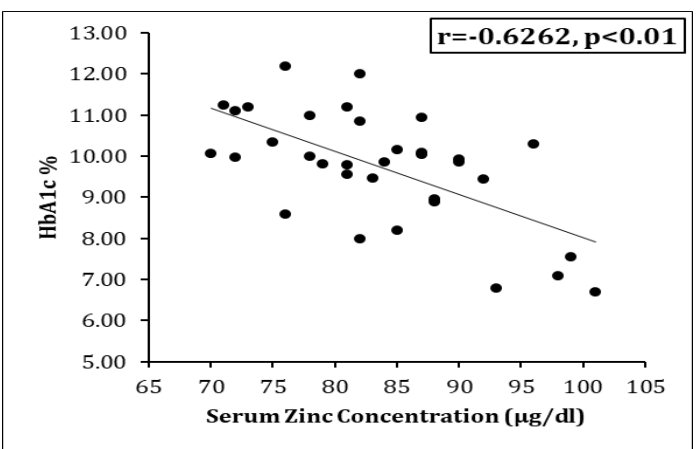

Fig. 1: Negative correlation of serum zinc concentration with $\mathrm{HbA1c \%}$ in Diabetics with complications

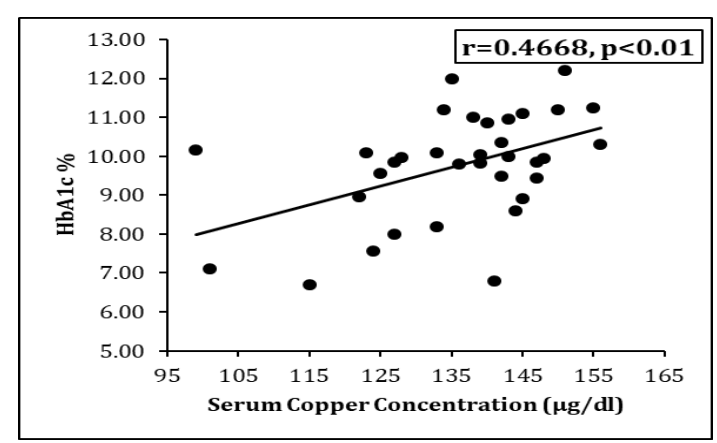

Fig. 2: Positive correlation of serum copper concentration with $\mathrm{HbA1c \%}$ in Diabetics with complications

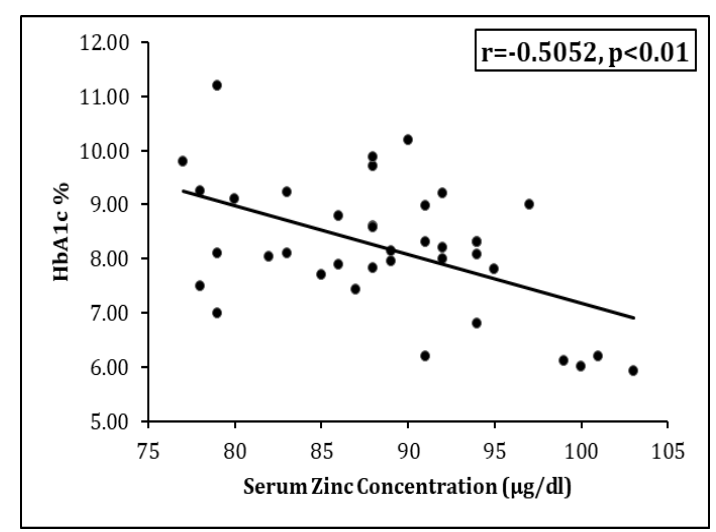

Fig. 3: Negative correlation of serum zinc concentration with $\mathrm{HbA1c \%}$ in Diabetics without complication

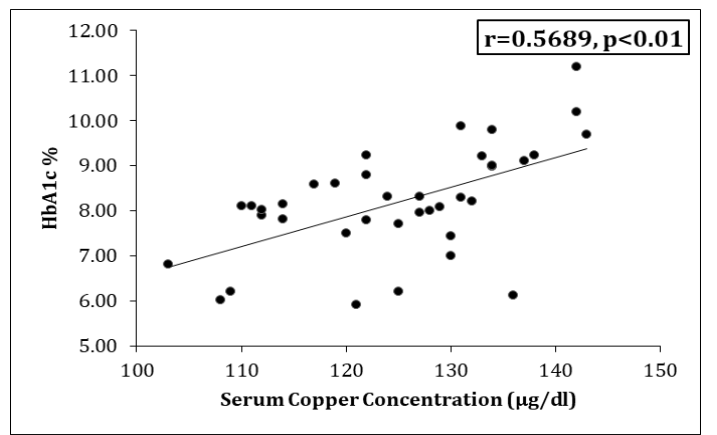

Fig. 4: Positive correlation of serum copper concentration with $\mathrm{HbA1c \%}$ in Diabetics without complications

\section{Discussion}

The number of patients suffering from diabetes mellitus was reported to be over 200 million people worldwide. Majority of it being suffering from noninsulin dependent type 2 diabetes mellitus. It is mainly characterised by insulin resistance in peripheral tissues along with defective insulin secretion from beta cells of the pancreas. ${ }^{5}$ As we know many trace elements are of prime importance for metabolism in human body. Numerous studies have demonstrated that trace element as zinc, copper, chromium, magnesium, selenium and molybdenum have essential role in insulin action and carbohydrate metabolism. ${ }^{11}$

In our study, serum zinc level was significantly lower in diabetic patients (with complications and without complications) compared to the healthy control group, which is in line with the findings of Puri $\mathrm{M}$ et al., ${ }^{2}$ Olaniyan OO et al, ${ }^{3}$ Devi TR et $\mathrm{al}^{4}$ and Supriya MS et al. ${ }^{5}$ Zinc is essential for the correct processing, storage, secretion, and action of insulin in beta ( $\beta$ )-cells of pancreas. Insulin is stored inside secretory vesicles or granules. Six insulin monomers require two $\mathrm{Zn}^{++}$ ions to form the hexameric-structure on which maturated insulin crystals are based. ${ }^{12}$ Some previous studies indicated that the lower serum zinc in diabetics may be due to diabetes related hyperzincuria and impaired gastrointestinal absorption of zinc. ${ }^{13}$ In addition to the findings that zinc levels are often low in diabetic, it is also felt that zinc (along with other micronutrients) may participate as an integral 
component of antioxidant enzymes. Decrease in intracellular zinc and zinc dependent antioxidant enzyme lead to an increase in intracellular oxidant and free radicals- that associated with complications of diabetes. ${ }^{5}$ These findings acclaim that decrease serum zinc level may be related with the development and progression of diabetic complications.

Copper metabolism in diabetic is altered. Many previous researchers have reported increase in copper level in complicated cases of diabetes mellitus. Our study results showed that serum copper level is significantly higher in diabetic patients (with complications and without complications) as compared to normal healthy control. Similar observation was reported by Olaniyan $\mathrm{OO}$ el $\mathrm{al}^{3}$, Devi TR et al., ${ }^{4}$ Supriya MS et al. ${ }^{5}$ and Kumar DA et al. ${ }^{6}$ In previous studies it has been already proved that copper causes oxidative stress. Majority of plasma copper present is transported bound to ceruloplasmin (>95\%). The remaining copper is bound to albumin, transcuprein and copper-amino acid complexes. ${ }^{14}$ Usually, level of serum copper and ceruloplasmin raised in patients of type 2 diabetes mellitus ${ }^{2}$. Because of its chemical property to take part in redox reactions, copper is powerful cytotoxic element in its free form. Free copper readily participates in redox reactions like, Heiber-Weiss reaction and Fenton reaction to generate reactive oxygen species and free radicals. ${ }^{5}$ Additionally, the raised serum copper level in type $2 \mathrm{DM}$ patients might also be attributed to persistent hyperglycaemia, which stimulates glycation and causes release of copper ions from copper binding sites of proteins. The released copper ions into blood further increases the oxidative stress so that, Advanced Glycation End products are formed. And it has been already proven that Advanced Glycation End products are involved in the pathogenesis and progression of diabetic complications. ${ }^{15,16}$

In present study, we have also observed significant $(p<0.01)$ positive correlation between serum copper and $\mathrm{HbA} 1 \mathrm{c} \%$ level in both diabetic groups with and without complications, that coincides well with the results of Evliyaoğlu $\mathrm{O}$ et $\mathrm{a}^{17}$. In present study, serum zinc level correlated (significantly $\mathrm{p}<0.01$ ) negative with $\mathrm{HbA} 1 \mathrm{c} \%$ in in both diabetic groups with and without complications. Same results were observed in Maher MA et al ${ }^{18}$ and Jyothirmayi B et al. ${ }^{19}$

In conclusion, above said alterations are the cause or consequence of diabetes mellitus remains yet to be determined but its strong association with pathogenesis of type 2 diabetes mellitus and its complications suggests the role played by trace elements (Serum zinc and copper) in glucose disposal. Impaired trace elements (Serum zinc and copper) metabolism to be an important influencing factors for diabetic patients for development and progression of complications. The decreased serum zinc and increased serum copper level in diabetics mainly disturb the homeostasis between oxidative stress and anti-oxidant mechanism, resulting in development of complications in diabetics. Based on the findings it may be beneficial to evaluate trace elements in early stage of diabetic patients as a part of the screening process in the risk detection and progression of diabetic complications.

\section{References}

1. Wild SH, Roglic G, Green A, Sicree R, King H. Global prevalence of diabetes: estimates for the year 2000 and projections for 2030. Diabetes care. 2004;27(5):1047-53.

2. Puri M, Gujral U, Nayyar SB. Comparative study of serum zinc, magnesium and copper levels among patients of type 2 diabetes mellitus with and without microangiopathic complications. Innovative Journal of Medical and Health Science. 2013;3(6):274-8.

3. Olaniyan OO, Awonuga MA, Ajetunmobi AF, Adeleke IA, Fagbolade OJ, Olabiyi KO, et al. Serum copper and zinc levels in Nigerian type 2 diabetic patients. African Journal of Diabetes Medicine. 2012;20(2):36-8.

4. Devi TR, Hijam D, Dubey A, Debnath S, Oinam P, Devi NG, et al. Study of serum zinc and copper levels in type 2 diabetes mellitus. International Journal of Contemporary Medical Research. 2016;3(4):1036-40.

5. Supriya MS, Pinnelli VB, Murgod R, Raghavendra DS. Evaluation of serum copper, magnesium and glycated haemoglobin in type 2 diabetes mellitus. Asian J Pharm Clin Res. 2013;6(2):188-90.

6. Kumar DA, Priya VS, Jaiprabhu J, Ramalingam K. Serum copper and zinc levels significance in type 2 diabetic patients. J Med Sci Tech. 2014;3(2):79-81.

7. American Diabetes Association. Diagnosis and classification of diabetes mellitus. Diabetes Care 2010; 33Suppl1:S62-9.

8. Akita A, Yiamashita S. Estimation of Serum Copper. Clin Chem. 1989;35(4):552-4.

9. Makino T. A sensitive, direct colorimetric assay of serum zinc using nitro-PAPS and microwell plates. Clin Chim Acta 1991;197:209-20.

10. Jeppsson JO, Kobold U, Barr J, Finke A, Hoelzel W, Hoshino T, et al. Approved IFCC reference method for the measurement of $\mathrm{HbA} 1 \mathrm{c}$ in human blood. Clin Chem Lab Med. 2002;40(1):78-89.

11. Wiernsperger N, Rapin J. Trace elements in glucometabolic disorders: an update. Diabetol Metab Syndr. 2010;2:70.

12. Li YV. Zinc and insulin in pancreatic beta-cells. Endocrine.2014;45:178-89.

13. Chausmer AB. Zinc, insulin and diabetes. J Am College of Nutr. 1998;17(2):109-15.

14. Cunningham J, Leffell M, Mearkle P, Harmatz P. Elevated plasma ceruloplasmin in insulin-dependent diabetes mellitus: evidence for increased oxidative stressas a variable complication. Metabolism. 1995;44:996-9.

15. Quilliot D, Dousset B, Guerci B, Dubois F, Drouin P, Ziegler O. Evidence that diabetes mellitus favors impaired metabolism of zinc, copper, and selenium in chronic pancreatitis. Pancreas. 2001;22:299-306.

16. Mosad A, AbouSeif, Ab Allah Yousef. Evaluation of some biochemical changes in diabetic patients. Clinica Chemica Acta.2004;346:161-70.

17. Evliyaoğlu O, Kebapçılar L, Uzuncan N, Kılıçaslan N, Karaca B, Kocaçelebi R, et al. Correlations of Serum Cu, $\mathrm{Zn}, \mathrm{Mg}$ and $\mathrm{HbA} 1 \mathrm{c}$ in Type 2 and Type 2 Diabetes 
Mellitus. Turkish Journal of Endocrinology and Metabolism. 2004;2:75-9.

18. Maher MA, Shaaban RH. Study of serum Magnesium, Zinc, Copper and Glycohemoglobin in children with type 1 diabetes mellitus. Alexandria J Ped. 2002;16(2):285-9.

19. Jyothirmayi B, Vasantha M. Study of zinc and glycated $\mathrm{Hb}$ levels in diabetic complications. Int J Pharm Clin Res. 2015;7(5):360-3 